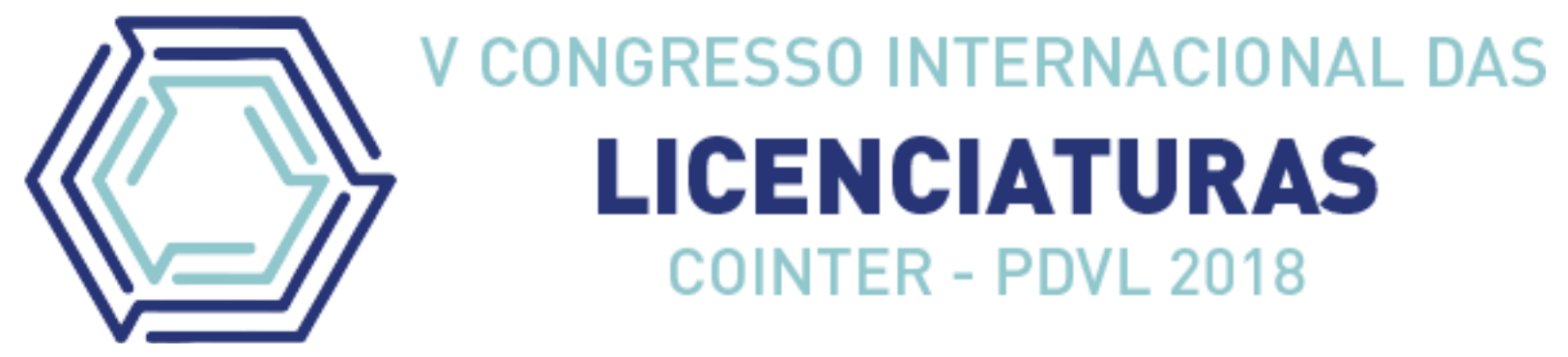

\title{
O ENSINO DA MATEMÁTICA COMO FORTALECIMENTO DA IDENTIDADE DO POVO INDÍGENA XUKURU DO ORORUBÁ-PE
}

\section{THE TEACHING OF MATHEMATICS AS STRENGTHENING THE IDENTITY OF INDIGENOUS PEOPLE XUKURU DO ORORUBÁ-PE}

\begin{abstract}
Apresentação: Relato de Experiência
Maria Marcela Lima de Moura ${ }^{1}$, Licenciatura em Matemática, Instituto Federal de Educação,

Ciência e Tecnologia de Pernambuco, marcela9594@gmail.com

Ana Catarina Monteiro ${ }^{2}$; Licenciatura em Matemática, Instituto Federal de Educação, Ciência e Tecnologia de Pernambuco, catarina.raiotur@hotmail.com

Natália Oliveira de Souza ${ }^{3}$, Licenciatura em Física, Instituto Federal de educação, Ciência e Tecnologia de Pernambuco, natyy_souza@outlook.com; Tiago Beserra Maciel, Mestre em Matemática pela Universidade Estadual da Paraíba, PROFMAT, Licenciando em Matemática pelo Instituto Federal de Pernambuco, tiagoprofxukuru@gmail.com ${ }^{1}$
\end{abstract}

\section{DOI: https://doi.org/10.31692/2358-9728.VCOINTERPDVL.2018.00290}

\section{Introdução}

Considerada uma ferramenta capaz de articular seus conhecimentos na resolução de problemas, a matemática é uma disciplina que necessita estar contextualizada. Apesar disso, em diversas vezes o conhecimento matemático é imposto ao aluno sem levar em consideração o seu contexto vivenciado. E abordar a matemática no ensino indígena requer pensar em alternativas metodológicas com ênfase na cultura e o meio social em que vivem.

A realidade das escolas para a maioria dos estudantes apontam que "[...] os conceitos vistos na escola são tão distantes das suas vivências, que, por isso, não se sentem motivados em aprender os conteúdos ou, quando os aprendem, é apenas para tirar nota nas avalições." (DOMINGUES, p.35, 2003). Nesse sentido, percebe-se que existe uma distância entre o

Maria Marcela Lima de Moura ${ }^{1}$, Licenciatura em Matemática, Instituto Federal de Educação, Ciência e Tecnologia de Pernambuco, marcela9594@gmail.com

Ana Catarina Monteiro ${ }^{2}$; Licenciatura em Matemática, Instituto Federal de Educação, Ciência e Tecnologia de Pernambuco, catarina.raiotur@hotmail.com

Natália Oliveira de $\mathrm{Souza}^{3}$, Licenciatura em Física, Instituto Federal de educação, Ciência e Tecnologia de Pernambuco, natyy souza@outlook.com; Tiago Beserra Maciel ${ }^{1}$, Mestre em Matemática pela Universidade Estadual da Paraíba, PROFMAT, Licenciando em Matemática pelo Instituto Federal de Pernambuco, tiagoprofxukuru@gmail.com ${ }^{1}$ 
conhecimento e a realidade. Deste modo, a Etnomatemática enfatiza justamente essa questão, propondo que seja aprendida a matemática da sua comunidade ou de sua etnia para se alcançar uma aprendizagem significativa, na qual os conhecimentos vividos são utilizados (DOMINGUES, 2003).

Em vista disso, a educação escolar indígena do povo Xukuru do Ororubá se dá de forma específica e diferenciada, onde o professor deve relacionar o conteúdo da Base Nacional Comum Curricular com a realidade do povo para que assim o estudante receba uma formação cabal. Assim, Assis (2014, p.26) afirma que "a etnomatemática representa um caminho para uma educação renovada em que a Matemática pode propiciar questionamentos sobre as situações reais vivenciadas pela sociedade." Deste modo, se faz necessário este liame entre a realidade do povo e os conteúdos globais, para que ao mesmo tempo em que o estudante aprende algo novo possa refletir sobre a sua realidade.

Pensando nisso, o presente relato de experiência refere-se a uma intervenção realizada na turma do $6^{\circ}$ ano A do Ensino Fundamental da Escola Estadual Indígena Ororubá, localizada no Território Indígena Xukuru do Ororubá no município de Pesqueira-PE. Na qual, o tema proposto foi potenciação e radiciação, tendo por objetivo fazer o estudo das operações matemáticas ao mesmo tempo em que se trabalhavam dados históricos do povo, visando fortalecer a sua identidade.

\section{Relato de Experiência}

Em todo grupo social há um jeito próprio de entender e explicar algo, e a educação indígena exige "[...] um tratamento diferenciado e próprio que busque a valorização do conhecimento tradicional vigente em seu meio, ao mesmo tempo em que forneça os instrumentos necessários para enfrentar o confronto com outras sociedades." (ASSIS apud RÊGO e PEREIRA, 2014, p.36).

Deste modo, foi pensada em atividades que os estudantes pudessem aplicar saberes da potenciação e radiciação ao mesmo tempo em que refletiam sobre a realidade e história do seu povo. A início foram relembrados os procedimentos para solucionar uma potenciação e uma radiciação, posteriormente foi distribuída uma atividade xerocada onde os estudantes fariam a leitura das questões e responderiam através de potenciação e radiciação informações sobre a história do povo. 
Imagem 1: Atividade xerocada. Fonte: Própria

\begin{tabular}{|c|c|}
\hline $\begin{array}{l}\text { 4.Francisco de Assis Araújo- Xikão foi nomeado cacique do } \\
\text { povo Xukuru do Ororubá há } 5^{2}+2^{2} \text { anos. Há } 5^{2}+3 \text { anos liderou } \\
\text { a primeira retomada na aldeia Pedra D'Água dando início ao } \\
\text { processo de reconquista do território. Território este que foi } \\
\text { identificado há } 4^{2}+3^{2}+2^{2} \text {, demarcado há } 5^{2}-2 \text { anos e } \\
\text { homologado há } 4^{2}+1 \text { anos. }\end{array}$ & $\begin{array}{l}\text { 4.Francisco de Assis Araújo- Xikão foi nomeado } \\
\text { cacique do povo Xukuru do Ororubá há } 5^{2}+2^{2} \text { anos. Há } \\
5^{2}+3 \text { anos liderou a primeira retomada na aldeia Pedra } \\
\text { D'Água dando início ao processo de reconquista do } \\
\text { território. Território este que foi identificado há } \\
4^{2} \oplus 3^{2} \oplus 2^{2} \text {, demarcado há } 5^{2}-2 \text { anos e homologado há } \\
4^{2}+1 \text { anos. }\end{array}$ \\
\hline $\begin{array}{l}\text { Preencha o trecho com as respostas: } \\
\text { Francisco de Assis Araújo- Xikão foi nomeado cacique do povo } \\
\text { Xukuru do Ororubá há } \\
\text { primeira retomada na aldeia Pedra D Á Água dando início ao a } \\
\text { processo de reconquista do território. Território este que foi } \\
\text { identificado há } \\
\text { homologado há ___anos. }\end{array}$ & $\begin{array}{l}\text { Preencha o trecho com as respostas: } \\
\text { Francisco de Assis Araújo- Xikão foi nomeado cacique } \\
\text { do povo Xukuru do Ororubá há } 29 \text { anos. Há } 28 \\
\text { anos liderou a primeira retomada na aldeia Pedra } \\
\text { D'Água dando início ao processo de reconquista do } \\
\text { território. Território este que foi identificado há } \\
29 \text {, demarcado há } 23 \text { anos e homologado } \\
\text { há } 17 \text { anos. }\end{array}$ \\
\hline
\end{tabular}

Imagem 2: Atividade xerocada. Fonte: Própria

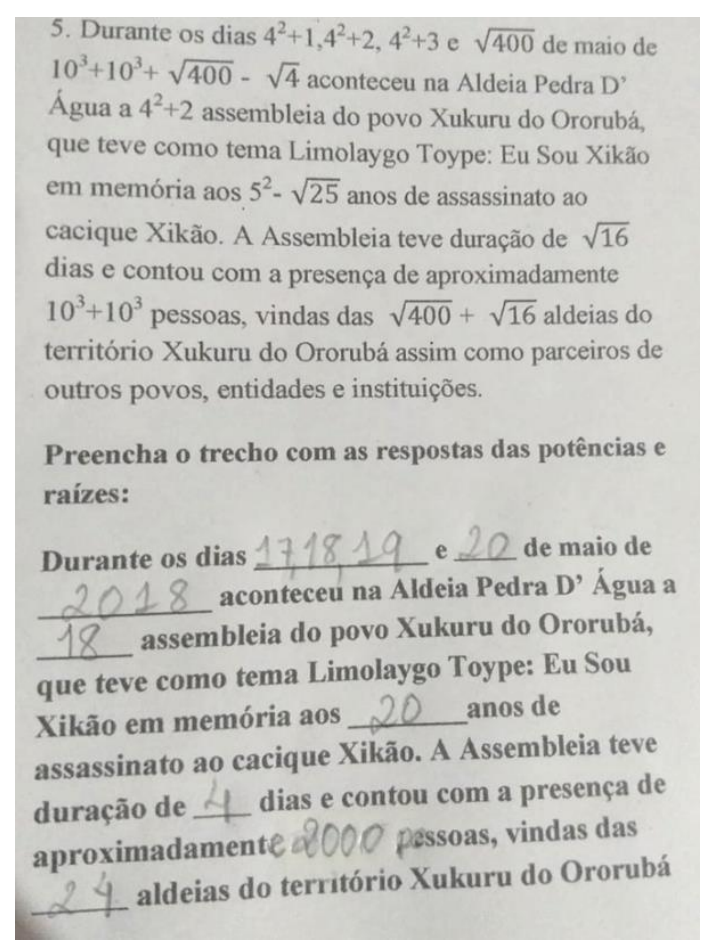

A aplicação da atividade foi dividida em duas etapas, com duas atividades distintas, A primeira atividade propiciou aos estudantes um momento de reflexão sobre o passado do seu povo, assim como o processo de lutas e conquistas. A segunda atividade propiciou um momento de reflexão sobre o momento atual, onde o povo realiza um evento para discutir o seu projeto de futuro. E ao mesmo tempo ambas trazem a abordagem matemática de modo a levar os estudantes a perceberem a importância da mesma no cotidiano e que através dela se podem ter registros de dados históricos.

As atividades trazem consigo também o fortalecimento da identidade do ser indígena, 
pois o estudante está reafirmando e interpretando a sua própria história. Faz-se necessário mostrar ao estudante que ele está inserido no mundo matemático e vice-versa, valorizando a sua participação enquanto pessoal política e social ao mesmo tempo em que é um instrumento de ensino- aprendizagem.

\section{Considerações}

Através da experiência foi possível observar que os estudantes tiveram uma maior interação, pois ao perceberem que as atividades traziam informações que aconteceram dentro do seu povo, ficaram curiosos para descobrirem quando tinha acontecido e logo utilizaram os saberes matemáticos para encontrar as respostas, as atividades também possibilitaram que os estudantes fizessem o uso de saberes adquiridos anteriormente. Deste modo, percebe-se que utilizar a realidade dos estudantes para facilitar o processo de ensino-aprendizagem, mostrando para eles que é possível aprender ao mesmo tempo em que se faz uma reflexão sobre a sua realidade, é uma alternativa metodológica que valoriza processos significativos de aprendizagem.

\section{Referências}

ASSIS, Francisco Guimarães de. Etnomatemática: o ensino da matemática na educação indígena. 2014. 48f. Monografia (Especialização em Fundamentos de Educação: práticas pedagógicas interdisciplinares) - Universidade Estadual da Paraíba, João Pessoa, 2014.

DOMINGUES, K. C. M. O currículo com abordagem Etnomatemática. Educação Matemática em Revista. São Paulo, v. 10, n. 14, p. 35-44. Ago. 2003. 